AGRICULTURE AND BIOLOGY JOURNAL OF NORTH AMERICA

ISSN Print: 2151-7517, ISSN Online: 2151-7525, doi:10.5251/abjna.2011.2.4.665.672

(C) 2011, ScienceHu $\beta$, http://www.scihub.org/ABJNA

\title{
Effects of poultry dropping on the biologically active compounds in capsicum annuum L (var. Nsukka yellow) \\ ${ }^{1 *}$ Ademoyegun, O. T., ${ }^{2}$ Fariyike T. A, ${ }^{2}$ Aminu-Taiwo R.B \\ ${ }^{1}$ Department of Product Deveploment, ${ }^{2}$ SpiceProgramme, National Horticultural Research Institute, P.M.B 5432, Idi-ishin, Ibadan.
}

\begin{abstract}
The aim of this study was to analyze the effect of poultry dropping on changes in total carotenoid, phenolic content, vitamin C, capsaicin and antioxidant activity assay by reducing power and free radical scavenging activity in capsicum annuum $L$ (var. Nsukka yellow). Five poultry dropping ( 0 , $5,10,15,20$ ton/ha levels were observed from 2008/2009 dry season on these bioactive compounds. The content of capsaicin responsible for the pungency of peppers varied between 38.1 and $51.4 \mathrm{mg} / \mathrm{g}$ dry fruit. Poultry dropping of $20 \mathrm{ton} / \mathrm{ha}$ level had the highest phenolic content, capsaicin and antioxidant activities. No relationships between the levels of biologically active compounds represented by vitamin $\mathrm{C}$ and carotenoids and the way of fertilization were observed. A strong correlation were observed between pheolic content and antioxidant activity as measured by reducing antioxidant power and free radical (1, 1-diphenyl-2-picrylhydrazyl, DPPH) scavenging assays. The study proposed the nutritional significance of consuming Nsukka yellow pepper cultivated with organic manure because of enhanced functional properties.
\end{abstract}

Keywords:Total carotenoids, Phenolic content, vitamin C, capsaicin, reducing power and Nsukka yellow pepper.

\section{INTRODUCTION}

Higher quality standards, better taste and greater satisfaction represent consumers' motives for the purchase of fruit and vegetables from organic or low input farming Heaton (2001). Generally, many plant crops are known for their richness in micronutrients and dietary fibre, thus their consumption has been distinctly recognized as being important factor for good health. It should be noted, however, that the influence of way of farming on the overall composition of organic crops as compared to conventional products has not been fully assessed until now (Worthington, 1998; Williams, 2002). This highlights how little we know about the impact of food on health, and the need for more and in particular better research (Brandt and Leifert, 2005).

Pepper is a vegetable of importance in human nutrition. In recent years, peppers have grown in popularity, and a wide number of varieties are now available in the grocery stores. Peppers are good sources of vitamins $C$ and $E$, provitamin $A$, and carotenoids (Materska and Perucka, 2005). Peppers also contain various phenolics,. flavonoids and Carotenoids (Lee et al., 1995;Amakura et al., 2002;Delgado- Vargas and Paredes-Lopez, 2003;Materska and Perucka, 2005). Carotenoids are important colorants in vegetables, which often impart orange and red colors (Delgado-Vargas and Paredes-Lopez, 2003). Carotenoids in peppers include capsanthin and carotene(Howard et al., $2000)$. The yellow-orange color of peppers is formed by $\alpha$ - and $\beta$-carotene, zeaxanthin, lutein, and $\beta$ cryptoxanthin (Howard et al., 2000).These compounds are antioxidants and can reduce harmful oxidation reactions in human body; thus consumption of peppers may prevent various diseases associated with free radical oxidation, such as cardiovascular disease, cancer, and neurological disorders (Doll, 1990; Hollman and Katan, 1999; Harborne and Williams, 2000; Delgado- Vargas and ParedesLopez, 2003; Shetty, 2004).

The group of pungent components peculiar to the fruits of Capsicum plants is called capsaicinoids. Capsaicinoids are produced in glands on the pepper placenta and on the white ribs that run down the middle, and along the sides, of a pepper. As a result, the glands and white ribs are the hottest parts of a red pepper. Since the seeds are in close contact with the ribs, they are also often hot (Bosland, 1992; Dong, 2000). (Govindarajan, 1985; Bosland, 1994) determined that there are great diversities in the contents and composition of capsaicinoids among fruits of Capsicum species, and even among cultivars. The environment, especially the climate, light, soil, moisture, fertilization and temperature 
during plant growth, is considered to have an impact on capsaicinoid levels, as does the age of the fruit (Estrada et al., 2002; Titze et al., 2002).

Capsaicinoids also have strong physiological and pharmacological properties. In addition to its widespread use as a neuropharmacological tool, capsaicin is of great medical value and it has been reviewed to evaluate its effect in treatment of painful conditions such as: rheumatic diseases, cluster headache, painful diabetic neuropathy, postherpetic neuralgia, etc Tsuchiya (2001). They decrease the myocardial and aortic cholesterol levels even when used at low levels in the diet. In recent years, capsaicinoids have been studied and found to be effective treatment for a number of sensory nerve fiber disorders including arthritis, cystitis, human immunodeficiency virus, etc Howard et al. (1994). They have also been reported as having an antioxidant and antibacterial effect on a certain group of bacteria (Henderson and Slickman, 1999; Dorantes et al., 2000).

Vitamin $C$ is another functional and nutritional constituent of pepper fruit, well-known as being an antioxidant and a biologically active compound. The above-mentioned composition of Capsicum fruit can vary greatly by genotype and maturity. The content of carotenoids and ascorbic acid of pepper fruit increases upon maturation Govindarajan (1985). They are also influenced by growing and processing conditions (Hornero-Mendez et al., 2000; Russo and Howard, 2002).

Therefore, the present study was conducted to determine the carotenoids, capsaicinoids, ascorbic acid contents and phenolic content in capsicum annuum L (var. Nsukka yellow) at different poultry dropping fertilization condition $(0,5,10,15,20)$ ton/ha. Also to determine the antioxidant activity using DPPH free radical scavenging activity and reducing power assay in the pepper extract. It is of great interest to know effect of different poultry dropping fertilization conditions on nutritive composition and biological properties.

\section{MATERIALS AND METHODS}

The experiment was carried out at the National Horticultural Research Institute (NIHORT) vegetable experimental field in Ibadan latitude $7^{0} 22^{\prime} \mathrm{N}$ Longitude $3^{0} 58^{\prime} \mathrm{E}$ and covers an area of 304 ha. Nsukka yellow pepper was obtained from experimental plot in year 2008/2009. Five different fertilization regimes were employed in this experiment.
0 - Control farming (Not fertilized with poultry manure)

$5-5$ ton/ha of poultry dropping

$10-10$ ton/ha of poultry dropping

$15-15$ ton/ha of poultry dropping

$20-20$ ton/ha of poultry dropping

Phenolic content:Total soluble phenols, in ethanol extracts, were determined with Folin-Ciocalteau reagent using the method of (Slinkard and Singelton, 1997). Fresh peppers $(2 \mathrm{~g})$ were thoroughly crushed and homogenized in $10 \mathrm{ml}$ of $80 \%$ ethanol containing $1 \% \mathrm{HCl}$. The homogenate was placed in capped test tubes and heated at $60{ }^{\circ} \mathrm{C}$ in a water-bath for $60 \mathrm{~min}$. This step helps to complete the extraction of the phenolics as well as to destroy ascorbic acid to a large extent. The reducing property of ascorbic acid has been shown to interfere in estimation of phenols by Folin's reagent. The extract was cooled and centrifuged at $10,000 \mathrm{rpm}$ for $15 \mathrm{~min}$ at $4{ }^{\circ} \mathrm{C}$. The resulting supernatant was collected and the pellet reextracted and the supernatants were pooled together. The final extract was concentrated with water -bath and the volume reduced to $20 \mathrm{ml}$. The same extract was used for the estimation of total phenolics and antioxidant activities. Results for phenolics were expressed as $\mathrm{mg} \mathrm{100/g}$ fresh weight (fw) catechin equivalent.

Total carotenoids: The extraction of carotenoids was carried out according to the method described by (Mı' nguez-Mosquera and Hornero-Me' ndez, 1993). A known weight $(2 \mathrm{~g})$ of fresh sample was extracted with acetone in mortar and pestle. Extractions were repeated until the complete exhaustion of colour (usually 4-5 extractions were enough). All extractions were pooled in a separating funnel and shaken with diethyl ether. A sufficient quantity of $10 \% \mathrm{NaCl}$ was added at the end to facilitate separation of the two phases. Aqueous phase was discarded. The lipophilic phase was washed with $100 \mathrm{ml}$ of an anhydrous $\mathrm{Na}_{2} \mathrm{SO}_{4}(2 \%)$ solution to remove all the remaining water. It was saponified with the addition of $40 \mathrm{ml}$ of $10 \% \mathrm{KOH}$ in methanol and shaken vigorously before being left in a dark place for $1 \mathrm{~h}$. After addition of water, the pigments were subsequently extracted with diethyl ether, evaporated in a rotary evaporator and then made up to $25 \mathrm{ml}$ with acetone. One millilitre aliquot of this solution was centrifuged at $12,000 \mathrm{rpm}$ and stored at $-20{ }^{\circ} \mathrm{C}$ until analysed. Losses occurring during the process were monitored with the use of all-trans $\beta$-apo-80-carotenal as internal standard. All analysis was carried out in 
Agric. Biol. J. N. Am., 2011, 2(4): 665-672

triplicate. Because of non availability of standards for different carotenoids, total carotenoids were estimated by taking the absorbance of extracts at $450 \mathrm{~nm}$.

Determination of capsaicin content: Capsaicin content in the samples was estimated by spectrophotometric measurement of the blue coloured component formed as a result of reduction of phosphomolybdic acid to lower acids of molybdenum (Sadasivam and Manikkam, 1992). Two grams of dry sample was extracted with $10 \mathrm{ml}$ of dry acetone using pestle and mortar. The extract was centrifuged at $10,000 \mathrm{rpm}$ for $10 \mathrm{~min}$ and $1 \mathrm{ml}$ of supernatant was pipette into a test tube and evaporated to dryness in a hot water-bath. The residue was then dissolved in $0.4 \mathrm{ml}$ of $\mathrm{NaOH}$ solution and $3 \mathrm{ml}$ of $3 \%$ phosphomolybdic acid. The contents were shaken and allowed to stand for $1 \mathrm{~h}$. The solution was filtered to remove any floating debris and centrifuged at $5000 \mathrm{rpm}$ for $15 \mathrm{~min}$. Absorbance was measured for the clear blue solution, thus obtained, at $650 \mathrm{~nm}$ using reagent blank $(5 \mathrm{ml}$ of $0.4 \% \quad \mathrm{NaOH}+3 \mathrm{ml}$ of $3 \%$ phosphomolybdic acid). Capsaicin content calculated from the standard curve was expressed as $\mathrm{mg} / 100 \mathrm{~g}$ on dry basis.

Ascorbic acid content: Ascorbic acid was quantitatively determined according to 2,6 dichlorophenolindophenol-dye method as described by (Jones and Hughes, 1983) with slight modifications. The ascorbic acid in $10 \mathrm{~g}$ of fresh sample was extracted by grinding with a small amount of acid-washed quartz sand and 3\% metaphosphoric acid $(\mathrm{v} / \mathrm{v})$. The extract volume was made up to $100 \mathrm{ml}$, mixed and centrifuged at $3000 \mathrm{~g}$ for 15 min at room temperature. Ten milliliters were titrated against standard 2, 6-dichlorophenolindophenol dye, which was already standardized against standard ascorbic acid. Results were expressed on $\mathrm{mg} / 100 \mathrm{~g}$ fw.

Antioxidant assays: Antioxidant activity was determined by the 2, 2,-diphenyl- 2-picryl-hydrazyl (DPPH) radical scavenging activity (RSA) method of (Zhang and Hamauzu, 2004) with some modifications. An aliquot of $3.9 \mathrm{ml}$ of $0.1 \mathrm{mM}$ DPPH radical in methanol was added to a test tube with 0.1 $\mathrm{ml}$ of pepper extract. Instead of extract of pepper (Nsukka yellow), pure methanol was used as control. The reaction mixture was vortexed and left to stand at room temperature in the dark for $60 \mathrm{~min}$ before the decrease in absorbance at $517 \mathrm{~nm}$ was measured. Pure methanol was used to calibrate the spectrophotometer. Antioxidant activity was expressed as percentage inhibition of the DPPH radical and was determined by the following equation: \% RSA $=100 \times(1-A C / A D)$, where $A C$ is the absorbance of the solution when the extract has been added at a particular level, and $A D$ is the absorbance of the DPPH solution. The assays were carried out in triplicate and the results are expressed as mean values \pm standard deviations.

Reducing power: The reducing powers of the extracts from Nsuka yellow pepper were determined according to the method described by (Benzie and Strain, 1999). $1 \mathrm{ml}$ of aliquot of each extract and ascorbic acid standard $(0.1-0.5 \mathrm{mg} / \mathrm{m} 1)$ were mixed with an equal volume of phosphate buffer $(1.0 \mathrm{ml}$, $200 \mathrm{mM}, \mathrm{pH} 6.7)$ and $1 \%$ potassium ferricyanide $(1 \mathrm{ml})$ and then incubated at $50^{\circ} \mathrm{C}$ for $15 \mathrm{~min}$. After, $1 \mathrm{ml}$, $10 \%, w / v$ trichloroacetic acid was added to the mixture to stop the reaction, and then the mixture was centrifuged at $2790 \mathrm{~g}$ for $10 \mathrm{~min}$. $1 \mathrm{ml}$ of the supernatant was mixed with $1 \mathrm{ml}$ distilled water and $0.1 \% \mathrm{FeCl}_{3}(1 \mathrm{ml})$ and then the absorbance was measured at $700 \mathrm{~nm}$. The ascorbic acid equivalents were calculated using standard graph of ascorbic acid. The experiment was conducted in triplicate and values are expressed as ascorbic acid equivalent in mg per $100 \mathrm{~g}$ (mg AA eqv/g) of extract (mean $\pm \mathrm{sd}$ ).

\section{RESULT AND DISCUSSION:}

The focus of dietary antioxidant research in recent years has shifted from vitamin $C$, vitamin $E$ and $b$ carotene to phenolics. The established health benefits of phenolics, due to their free radical scavenging activities in vitro and in vivo biological systems (Powels and Ness, 1996) necessitates their quantification in foods. There is worldwide interest to identify difference fertilization condition with enhanced levels of polyphenolics for targeting increased functional properties in foods before we discuss the results on phenolics, it is important to mention that the Folin's test used overestimates the content of phenolic substances, since the reducing agents such as ascorbic acid present in the food can interfere in this assay. In the present study, the ethanolic extract was heated in a boiling water bath before estimation of total phenolics. Although the heating treatment results in destruction of ascorbic acid to a great extent, it is always necessary to apply a suitable correction factor to find the real phenolic content. This point has been emphasized recently by (George et al., 2004). The phenolic content of reduced ascorbic acid in Nsukka yellow pepper ranged from 120.82 to $214.56 \mathrm{mg} / 100 \mathrm{~g}$ fw (fig.I). A 
significant increase was observed in the phenolic content as the poultry manure increased. The highest was found in 20 ton/ha with phenolic content 214.56 $\mathrm{mg} / 100 \mathrm{~g} \mathrm{fw}$ (fig.l), the lowest was found in control 0 ton/ha (without manure) with phenolic content of $120.82 \mathrm{mg} / 100 \mathrm{~g} \mathrm{fw}$ (fig.l).

Phenolic compounds are found in both edible and inedible plants and they have been reported to have multiple bioactive effects, including antioxidant activity. The antioxidant activity of phenolic compounds is due to multi-mechanisms activities like quenching singlet, triplet oxygen and neutralizing free radicals. Extracts of fruits, vegetables and spices are rich in polyphenol increasingly of interest in the food industry.



Fig. 1:Phenolic content of Nsukka yellow pepper

Carotenoid and Ascorbic acid content: Peppers are also a good source of carotenoids, which can vary in composition and concentration owing to differences in genetics and maturation (Russo and Howard, 2002). During ripening of yellow peppers the green colour due to chlorophyll and carotenoids such as lutein disappear with the synthesis of chromoplast pigments. Carotenoids content ranged from 3.2 to 4.8 $\mathrm{mg} / 100 \mathrm{~g} \mathrm{fw}$ (fig. III), the highest content was found in 10 ton/ha of poultry dropping, the lowest in control with no organic manure (Fig.III). Total carotenoid was enhanced with organic manure, but increase in poultry dropping does not enhance the carotenoids (fig.III).
Capsaicin: Capsaicin (8-methyl-n-vanillyl-6-nonenamide) is the dominant pungency principle unique to the genus, Capsicum, which imparts flavour and also has therapeutic uses for its anticarcinogenic properties (Surh and Lee, 1996). The capsaicin which responsible for the pungency in pepper, varied between 38.1 and $51.4 \mathrm{mg} / \mathrm{g} \mathrm{dw}$ (fig.II). There was an increased in capsaicin content as the level of poultry manure increased. In our study when compare with the value of (Pino et al., 2007) (41.8 to $65.9 \mathrm{mg} / \mathrm{g} \mathrm{dw}$ ) capsaicin of Habanero chilli pepper which is hot, shown that Nsukka yellow pepper rich in capsaicin with the ranged from 38.1 and $51.4 \mathrm{mg} / \mathrm{g}$ dry fruit.

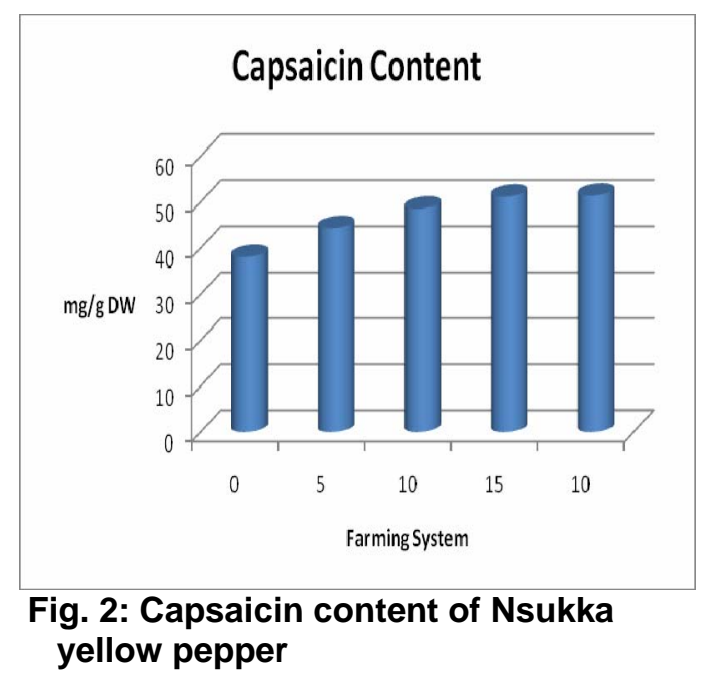

Vitamin C content ranged from 60.1 - 64.5 $\mathrm{mg} / 100 \mathrm{gfw}$ (fig.IV), highest content was found in 5 ton/ha of poultry manure, lowest in 15 ton/ha of poultry dropping (fig.IV). The vitamin C content does not influenced by the farming system. With regard to recommended dietary allowance (RDA), a $100 \mathrm{~g}$ serving of fresh pepper could supply more than $100 \%$ of RDA (60 mgday $^{-1}$ ) for vitamin C(fig.IV). However, Nsukka yellow pepper is a good source of ascorbic acid. No relationships between the levels of biologically active compounds represented by vitamin $\mathrm{C}$ and carotenoids and the way of fertilization were observed (fig.III and fig.IV). 
Agric. Biol. J. N. Am., 2011, 2(4): 665-672

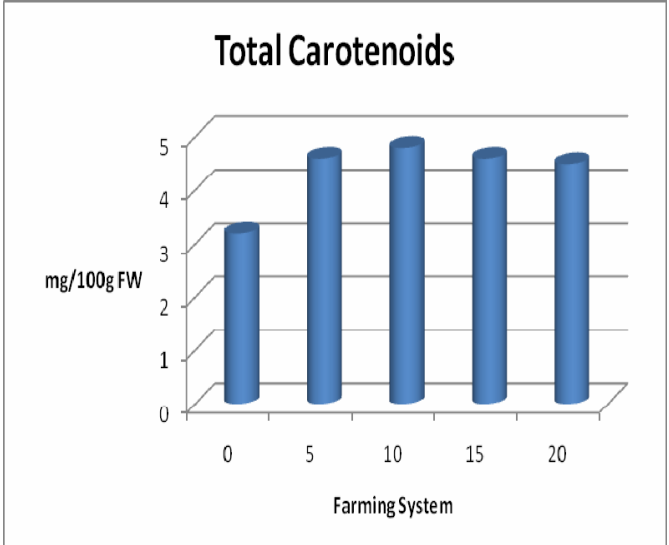

Fig. 3: Total carotenoids content of Nsukka yellow pepper

Antioxidant activity: The antioxidant activity of foods has been tested using a wide variety of methods. Antioxidant activity is the capacity to prevent auto-oxidation of free-radical mediated oxidation of the substrate when present in low concentration Halliwell (1992). In the present study, antioxidant activity was measured by two different methods, namely reducing power assay and free radical (DPPH) scavenging assay. Both these assays have been frequently used to assess antioxidant activity (Imeh and Khokhar, 2002; Ou et al., 2002). Reducing power reflects total antioxidant power involving the single electron transfer reaction, whereas DPPH is based on free radical scavenging activity (Ou et al., 2002). Antioxidant activity of reducing power ranging from 220.8 - $304.5 \mathrm{mg}$

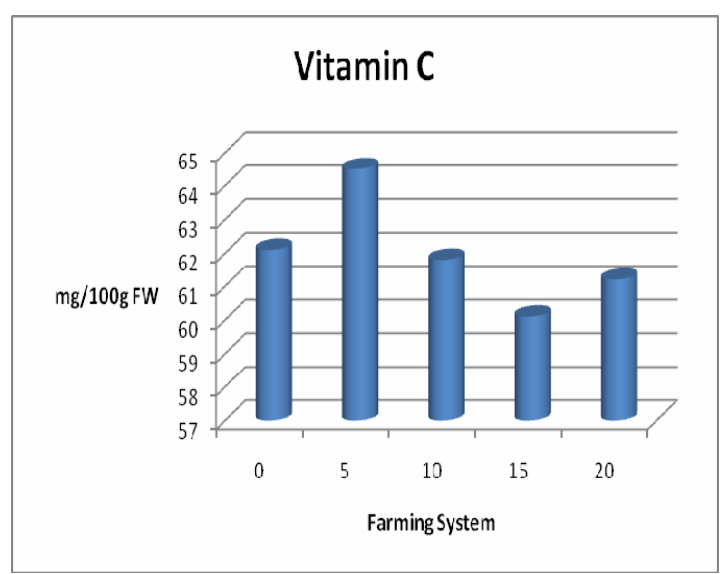

Fig. 4: Vitamin C content of Nsukka yellow pepper

AAeqv $/ 100 \mathrm{~g} \mathrm{fw}$ (fig.VI). Free radical scavenging activity (DPPH assay) varied from 76.4 to $87.4 \%$ inhibition (fig.V). Enhanced levels were observed in the two antioxidant activities assay as the level of poultry dropping increased. The importance of the antioxidant constituents of plant materials is in the maintenance of health and protection from coronary heart disease and cancer which is also raising interest among scientist, food manufacturers, and consumers. It is suggests that polyphenolic compounds have inhibitory effects on mutagenesis and carcinogenesis in humans, when up to $1.0 \mathrm{~g}$ was daily ingested from a diet rich in fruits vegetables and spices (Howard et al., 2000).



Fig. 6: Antioxidant activity of Stable radical in Nsukka yellow Reduce power assay 
Agric. Biol. J. N. Am., 2011, 2(4): 665-672

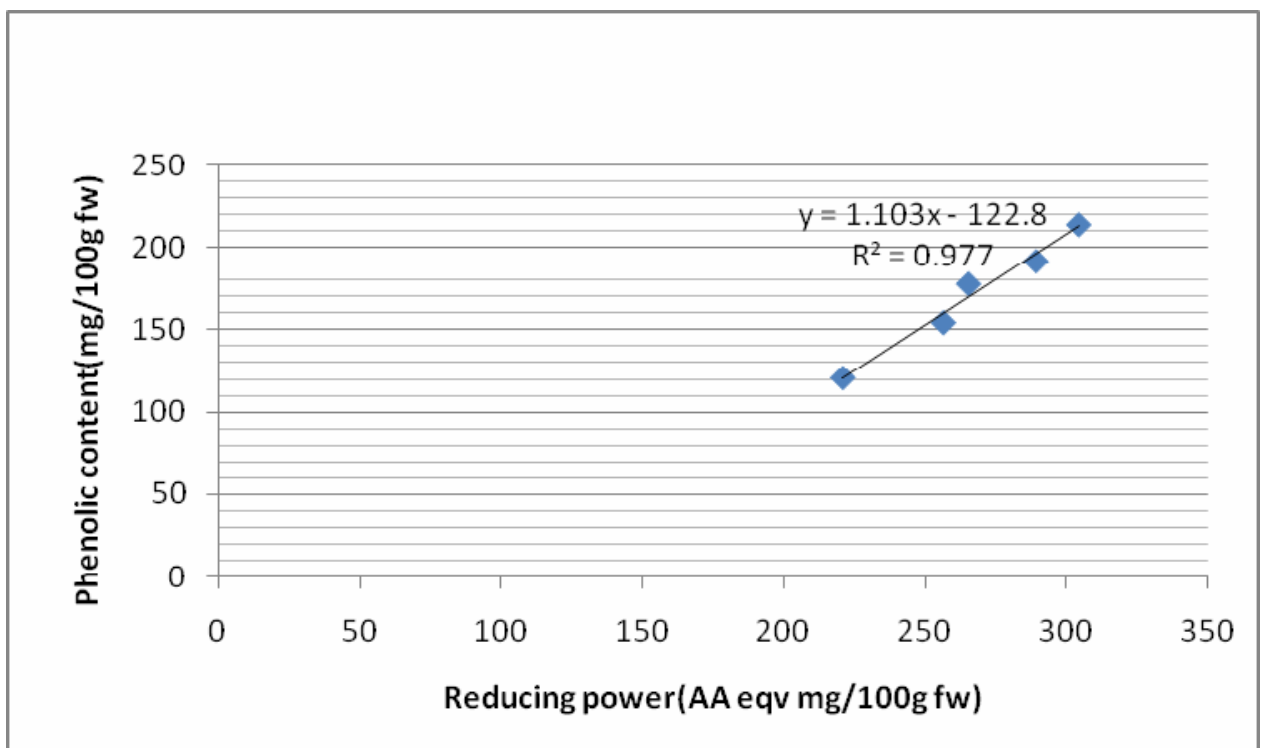

Fig.7: Correlation between phenolic content and antioxidant activity (reducing power

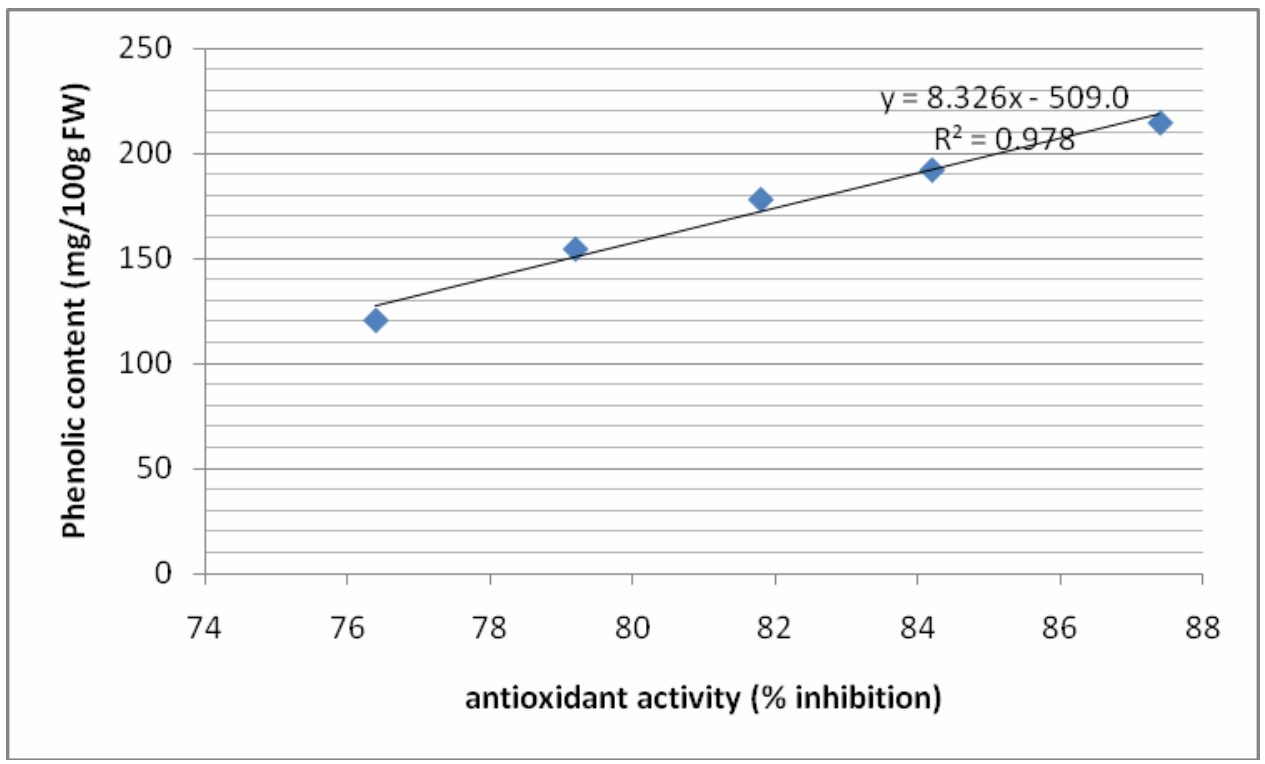

Fig.8: Correlation between phenolic content and antioxidant activity (DPPH assay).

Hence, it is important to examine the correlation between the content of the total polyphenols and the total antioxidant potential because some authors have reported that there is no correlation between the content of these main antioxidant compounds (Ou et al., 2002). The results obtained by us do not support these claims. The correlation analysis showed a strong relationship between phenolic content and antioxidant activity as measured by reducing power and free radical scavenging assay $(r=0.977$ reducing power, $r=0.978 \mathrm{DPPH}$ (fig. VII and fig.VIII). The literature reports concerning the relationship of phenols and antioxidant activity are in agreement with (Djeridane et al., 2006: Wong et al., 2006).

\section{CONCLUSION:}

Variation in total phenols, antioxidant activities, and capsaicin content were observed in the level of poultry dropping as it increased. Nutritionally, Nsukka 
yellow pepper is a good source of mixture of antioxidants including ascorbic acid, capsaicin, carotenoids and polyphenols.

Application of organic waste, poultry dropping increased the functional compounds of Nsukka yellow pepper significantly more than the control. In this study, numerous evidence have clearly shown that peppers contain phytochemical known as antioxidants or functional compounds, which assists in the prevention or treatment of painful conditions, cancer, stroke and other diseases when consumed in our diet. Applications of this organic waste have increased the optimal levels of functional compounds and also poultry dropping or waste is cheap to obtain. Hence, it is recommended for use since increase the amount of phytochemical will provide more health benefit for the people.

\section{REFERENCES:}

Amakura, Y.,Umino, Y., Tsuji, S., Ito, H., Hatano, T., Yoshida, T and Tonogai, Y (2002). Constituents and their antioxidative effects in eucalyptus leaf extract used as a natural food additive. Food Chem 77:47-56.

Benzie, I. E. F and Strain, J. J (1996). The ferric reducing ability of plasma (FRAP) as a measure of antioxidant power: the FRAP assay. Analytical Biochemistry, 239, 70-76.

Bosland, P.W (1992). Chiles: a diverse crop. Horticultural Technology 2 (1), 7-10.

Bosland, P. W (1994). Chiles: History, cultivation and uses. In G. Charalambous (Ed.), Spices, herbs and edible fungi (herbs) (pp. 347-366). Amsterdam: Elsevier.

Brandt, K., Leifert, C (2005). Which aspects of health are likely to be affected by our

choice of food quality, such as organic food, and how can we investigate this question?

http://orgprints.org/8427/01/brandt240 243.pdf

Delgado-Vargas, F and Paredes-Lopez, O (2003). Natural colorants for food and nutraceutical uses. Boca Raton, Fla.: CRC Press. pp 257-305.

Djeridane, A., Yousfi, M., Nadjemi, B., Boutassouna, D., Stocker, P and Vidal, N (2006). Antioxidant activity of some Algerian medicinal plants extracts containing phenolic compounds. Food Chemistry, 97, 654-660.

Doll, R (1990). An overview of the epidemiologic evidence linking diet and cancer. Proc Nutr Soc 49:119-31.

Dong, M.W (2000). How hot is that pepper? Today's Chemist at Work 9 (5), 17-20.

Dorantes, L., Colmenero, R., Hernandez, H., Mota, L., Jaramillo, M.E., Fernandez, E and Solano, C (2000).
Inhibition of growth of some foodborne pathogenic bacteria by Capsicum annuum extracts. International Journal of Food Microbiology 57, 125-128.

Estrada, B., Bernal, M. A., Diaz, J., Pomar, F and Merino, F (2002). Capsaicinoids in vegetative organs of Capsicum annnuum $L$. in relating to fruiting. Journal of Agricultural and Food Chemistry, 50, 1188-1191.

George, B., Kaur, C., Khurdiya, D.S and Kapoor, H.C (2004). Antioxidants in tomato (Lycopersicon esculentum) as function of genotype. Food Chemistry $84,45-51$.

Govindarajan, V. S (1985). Capsicum production, technology, chemistry and quality. 1. History, botany, cultivation and primary processing. Critical Review in Food Science Nutrition, 22(2), 109- 176.

Halliwell, B (1992). How to characterize biological antioxidants? Free Radical Research Communication $9,32$.

Harborne, J.B and Williams C.A (2000). Advances in flavonoid research since 1992. Phytochemistry $55: 481-504$.

Henderson, D.E and Slickman, A.M (1999). Quantitative HPLC determination of the antioxidant activity of capsaicin on the formation of lipid hydroperoxides of linoleic acid: a comparative study against BHT and melatonin. Journal of Agricultural and Food Chemistry 47, 2563-2570.

Heaton, S (2001): Organic farming, food quality and human health. A review of evidence. The Soil Association, Bristol, U.K., 1-87.

Hollman, P.C.H and Katan M.B (1999).Dietary flavonoids: intake, health effects and bioavailability. Food Chem Toxicol 37:937-42.

Hornero-Me' ndez, D., Guevara, R. G and Mı'nguezMosquera, M. I (2000). Carotenoid biosynthesis changes in five red pepper (Capsicum annuum L.) cultivars during ripening. Cultivar selection for breeding. Journal of Agricultural and Food Chemistry, 48, 3857-3864.

Howard, L. R., Smith, R. T., Wagner, A. B., Villalon, B and Burns, E. E (1994). Provitamin A and ascorbic acid content of fresh pepper cultivars (Capsicum annuum) and processed jalapenos. Journal of Food Science, $59,362-365$.

Howard, L. R., Talcott, S. T., Brenes, C. H and Villalon, B (2000). Changes in phytochemical and antioxidant activity of selected pepper cultivars (Capsicum species) as influenced by maturity. Journal of Agricultural and Food Chemistry, 48, 1713-1720.

Imeh, U and Khokhar, S (2002). Distribution of conjugated and free phenols in fruits: Antioxidant activity and 
cultivar variations. Journal of Agricultural and Food Chemistry 50, 6301-6306.

Jones, E., \& Hughes, R. E. (1983). Foliar ascorbic acid in some angiosperms. Phytochemistry, 22, 2493-2499.

Lee, Y., Howard, L. R and Villalon, B (1995). Flavonoids and antioxidant activity of fresh pepper (Capsicum annuum) cultivars. J. Food Sci. 60, 473-476

Materska, M and Perucka I (2005). Antioxidant activity of the main phenolic compounds isolated fromhot pepper $\begin{array}{llll}\text { fruit (Capsicum annuum L.). J Agric } & \end{array}$ FoodChem53:1750-6.

Mı́nguez-Mosquera, M. I and Hornero-Me' ndez, D (1993). Separation and quantification of carotenoid pigments in red peppers (Capsicum annuum) paprika and oleoresin by reversed-phase HPLC. Journal of Agricultural and Food Chemistry, 41, 1616-1620.

Ou, B., Huang, D., Hampschwoodwill, M., Flanagan, T. A., \& Deemer, E. K. (2002). Analysis of antioxidant activities of common vegetables employing oxygen radical absorbance capacity and FRAP assays: A comparative study. Journal of Agricultural and Food Chemistry, 50, 3122-3128.

Pino, J., Gonzälez. M., Ceballos, L., Centuriòn - Yah, AR., Trujillo - Aguirre, J., Latowonerie - Moreno, L and Sauri - Duch, E (2007) Characterization of total capsaicinoids, colour and violate compounds of harbanero chilli pepper ( capsicum chinense jack) cultivars grown in yucatan. Food Chemistry 104, 1682- 1686

Powels, J. W and Ness, A. R (1996). Fruits, vegetables and cardiovascular disease: A review. International Journal Epidemiology, 26, 1-13.

Russo, V.M and Howard, L.R (2002). Carotenoids in pungent and nonpungent peppers at various developmental stages grown in the field and glasshouse. Journal of the Science of Food and Agriculture 82, 615-624.
Sadasivam, S and Manikkam, A (1992). Capsaicin. In Biochemical methods for agricultural sciences ( $p p$. 193-194). New Delhi: Wiley Eastern Limited.

Shetty, K (2004). Role of proline-linked pentose phosphate pathway in biosynthesis of plant phenolics for functional food and environmental applications: a review. Process Biochem 39:789-803.

Slinkard, K and Singelton, V. L (1997). Total phenolic analysis, automation and comparison with manual methods. American Journal of Enology and Viticulture, 28, 4955 .

Surh, Y and Lee, S. S (1996). Capsaicin in hot chilli pepper, carcinogen or anticarcinogen. Food and Chemical Toxicology, 34, 313-316.

Titze, P. K., Hiepler, C., Seitz, E. M and Petz, M (2002). Pungency in paprika (Capsicum annuum). 1. Decrease of capsaicinoid content following cellular disruption. Journal of Agricultural and Food Chemistry, 50, 12601263.

Tsuchiya, H (2001). Biphasic membrane effects of capsaicin, an active component in Capsicum species. Journal of Ethnopharmacology 75, 295-299.

Williams, C. M (2002): Nutritional quality of organic foods: shades of grey or shades of green? Proceedings of Nutrition Society 61, 19-24.

Wong, C., Li, H., Cheng, $\mathrm{K}$ and Chen, F (2006). A systematic survey of antioxidant activity of 30 Chinese medicinal plants using the ferric reducing antioxidant power assay. Food Chemistry, 97, 705-711.

Worthington, V (1998): Effect of agricultural methods on nutritional quality: a comparison of organic with conventional crops. Alternative Therapies in Health and Medicine 4, 58-69.

Zhang, D and Hamauzu, Y (2004). Phenolics, ascorbic acid, carotenoids and antioxidant activity of broccoli and their changes during conventional and microwave cooking. Food Chemistry, 88, 503-509. 